\title{
MEDIDAS EXECUTIVAS ATÍPICAS CABEM NOS JUIZADOS ESPECIAIS?
}

\section{CAN ATYPYCAL EXECUTIVE MEASURES FIT THE SPECIAL COURTS?}

Marcos Youji Minami Doutor e Mestre em Direito Público (UFBA); Bacharel em Direito (UFC); Membro da Associação Norte e Nordeste de Professores de Processo (ANNEP) e do Instituto Brasileiro de Direito Processual Civil (IBDP); Professor da Universidade Regional do Cariri (URCA). Fortaleza/CE. E-mail: marcos.minami@urca.br.

Nadinne Sales Callou Esmeraldo Paes Mestre em Ciências Jurídico-Políticas (Universidade do Porto); Professora do Curso de Direito e pesquisadora dos temas Acesso à Justiça, Direito Civil e Direito da Criança e do Adolescente (UniFAP); Defensora Pública Estadual (DPGECE). Fortaleza/CE. E-mail: nadinnecallou@yahoo.com.br

Shayana Sarah Vieira de Andrade Mousinho Bacharelanda em Direito (URCA); pesquisadora dos temas relacionados aos Direitos Humanos Fundamentais (GEDHUFURCA) e Direito Internacional dos Direitos Humanos (GEDAI-UFC); bolsista FUNCAP-URCA. Fortaleza/CE. Email: shayana.mousinho@urca.br

RESUMO: A partir de uma decisão que negou medida coercitiva nos juizados com base na celeridade e informalidade, este artigo objetiva analisar se o uso de medidas executivas atípicas viola as normas fundamentais regentes dos juizados especiais estaduais e distrital. A pesquisa foi feita a partir de análise de doutrina e decisões que trataram do tema debatido,

\footnotetext{
${ }^{1}$ Artigo recebido em 13/04/2021 e aprovado em 07/07/2021.
} 
direta ou indiretamente. Conclui-se que os juizados especiais não se resumem à celeridade ou simplicidade e que o uso de medidas atípicas nessas estruturas não viola seus preceitos fundamentais e não é algo incompatível com a Lei 9.099/95.

PALAVRAS-CHAVE: Juizados Especiais; Celeridade; Medidas Executivas Atípicas.

\begin{abstract}
From a decision that denied the use of the coercive measures in small claim courts based on celerity and informality, this article aims to analyze if the usage of atypical executive measures violates the fundamental regimental norms of state and district' small plea courts. The research was made through the analyses of doctrine and decisions about the theme debated, direct or indirectly. The conclusion was that the small claim courts are not only celerity or simplicity. And, furthermore, the application of atypical measures into these structures does not violate its core rules and it is not incongruous with Law 9.099/95.
\end{abstract}

KEYWORDS: Small Claim Courts; Celerity; Atypical Executive Measures.

\title{
1. INTRODUÇÃO
}

Não é incomum lermos decisões proferidas nos juizados especiais fundamentadas na informalidade, celeridade ou simplicidade. Eis um exemplo de provimento nesse sentido, mas cujo número do processo não tivemos acesso:

"Em que pese a manifestação do ID XXXX, o Juizado Especial foi criado tomando-se como base os princípios da celeridade e simplicidade. Verifico não ser viável o deferimento das medidas coercitivas requeridas no ID XXXX, pois, uma vez deferidas, o processo se alongará ainda por muitos e muitos anos, o que foge totalmente do disposto no art. $2^{\circ}$ da Lei 9.099/95.".

A fundamentação extremamente deficiente dessa decisão é algo que chama a atenção imediatamente e é importante lembrar que motivação adequada não significa, necessariamente, vários parágrafos de argumentação. Isso não será analisado aqui, pois este artigo possui outro escopo, mas talvez este artigo responda a um questionamento: será que é verdade que a adoção de uma determinada medida coercitiva prolonga o processo "por muitos e muitos anos"? 
Revista Eletrônica de Direito Processual - REDP.

Rio de Janeiro. Ano 15. Volume 22. Número 3. Setembro a Dezembro de 2021

Periódico Quadrimestral da Pós-Graduação Stricto Sensu em Direito Processual da UERJ

Patrono: José Carlos Barbosa Moreira (in mem.). ISSN 1982-7636. pp. 732-743

www.redp.uerj.br

As medidas coercitivas consistem, em resumo, na ameaça de piora de situação jurídica do destinatário da ordem caso ele não a realize. Por exemplo: faça o que se pede, caso contrário, haverá pagamento de multa; pague a dívida de alimentos para não ir preso. Outra medida que alguns classificam como coercitiva (ou meio coercitivo de incentivo) é o oferecimento de alguma vantagem ao destinatário da ordem para que ele a realize ${ }^{2}$. Eis o exemplo: pague a dívida em até 3 dias que será concedido um parcelamento ou desconto.

$\mathrm{Na}$ situação acima, não é possível saber qual foi o meio requerido, nem se ele era típico ou atípico, mas o fato é que a sua negativa ocorreu a partir de preceitos fundamentais dos juizados especiais, constantes no art. $2^{\circ}$ da Lei 9.099/95. Tendo essa decisão como pretexto, este escrito pretende analisar se os meios executivos atípicos violam esses preceitos fundamentais ou outros enunciados da lei especial.

Algumas observações antes de começarmos.

Este não é um escrito para desvendar os critérios de aplicação dos meios executivos atípicos, embora, eventualmente, alguns deles sejam aqui apresentados para possibilitar algumas conclusões. Também não é um artigo que assume a possibilidade de quaisquer

\footnotetext{
${ }^{2}$ Há quem prefira chamar tais medidas de indutivas. Nesse sentido: MEIRELES, Edilton. "Medidas subrogatórias, coercitivas, mandamentais e indutivas no Código de Processo Civil de 2015". Revista de Processo, vol. 247, Set/2015. São Paulo: Editora Revista dos Tribunais, 2015. Versão eletrônica; MAZZEI, Rodrigo Reis; ROSADO, Marcelo da Rocha. "A cláusula geral de efetivação e as medidas indutivas no CPC/15". Grandes temas do novo CPC - Medidas Executivas atípicas/ Coords.: Eduardo Talamini, Marcos Y. Minami. Salvador: Jus Podivm, 2018. Não é essa, porém, a opção dos autores que incluem as medidas de incentivo no rol das medidas coercitivas (coerção por incentivo). Nesse mesmo sentido, entre outros: DIDIER JR. Fredie; CUNHA, Leonardo Carneiro da; BRAGA, Paula Sarno; OLIVEIRA, Rafael Alexandria de. Curso de direito processual civil: execução. 7. ed., rev., ampl. e atual. Salvador: JusPodivm, 2017, pp. 52-53; BORGES, Marcus Vinícius Motter. Medidas coercitivas atípicas nas execuções pecuniárias: parâmetros para a aplicação do art. 139, IV do CPC/2015. São Paulo: Thomson Reuters Brasil, 2019, p. 72. Sobre isso, é importante ressaltar que, em determinado momento na tramitação do atual CPC no Congresso Nacional, a redação original do atual art. 139, IV, mencionava apenas as medidas sub-rogatórias e mandamentais. Contudo, para evitar discussões por parte daqueles que entendem pela existência de outras espécies de meios executivos, como os indutivos e os mandamentais, resgatou-se o projeto original para constar do CPC estas últimas categorias. Isso ocorreu com a justificativa de se evitar confusões sobre quais medidas estariam afinal autorizadas pelo art. 139, IV. É o que se verifica na leitura da justificativa do Relatório da Comissão Temporária sobre o Substitutivo da Câmara dos Deputados: "convém rejeitar o inciso IV do art. 139, restabelecendo a versão do PLS para o dispositivo em pauta (inciso III do art. 118), por sua maior clareza, idônea a evitar dúvidas na definição do alcance das medidas coercitivas e sub-rogatórias"(Relatório da Comissão Temporária do Código de Processo Civil, sobre o Substitutivo da Câmara dos Deputados (SCD) ao Projeto de Lei do Senado (PLS) no 166, de 2010, que estabelece o Código de Processo Civil. Relator: Senador Vital do Rêgo, p. 87). Ou seja, no relatório que restabeleceu a atual versão do inciso IV, do art. 139, e que traz quatro tipos de medidas, reconheceu-se que há apenas duas delas: coercitivas e sub-rogatórias! Há quem prefira chamar a coerção por incentivo de sanção premial, expressão que, embora de uso corriqueiro, não é albergada pelo atual CPC; ou pelo verbete em inglês "nudge", expressão que os autores entendem por bem evitar para evitar ainda mais confusão sobre o tema, principalmente porque há palavras em português batizando o fenômeno.
} 
meios executivos atípicos. O objetivo é tão somente analisar se uma execução regida pela atipicidade é possível nos juizados especiais. Para analisar quais os critérios desses meios, o leitor deve buscar leitura específica para esse tema.

O enfoque são os juizados especiais no âmbito das Justiças Estaduais e Distrital. Não se falará, portanto, de eventuais peculiaridades que possam existir no âmbito dos Juizados Especiais da Justiça Federal ou dos Juizados Especiais da Fazenda Pública.

Para o atingimento dos objetivos propostos, serão utilizados, além de escritos específicos sobre os temas tratados, legislação e decisões.

\section{A IMPORTÂNCIA DOS JUIZADOS ESPECIAIS PARA ALÉM DA CELERIDADE E SIMPLICIDADE}

Nenhuma das três clássicas ondas de acesso à justiça propostas no Estudo de Florença que resultou, entre outras coisas, no livro "Acesso à Justiça"3, de Mauro Cappelletti e Bryant Garth, possuem a celeridade, a simplicidade ou a informalidade como motes principais.

É famoso o estudo sobre acesso à justiça citado e suas conclusões foram resumidas em três "ondas" ou "dimensões" renovadoras, merecedoras de atenção pelos juristas. De forma simplificada, podemos dizer que a primeira onda é focada nos obstáculos financeiros que impedem acesso à justiça; a segunda preocupa-se com a tutela coletiva; e a terceira, quase que residualmente, lida com vários aspectos relacionados aos órgãos de justiça, como suas estruturas físicas, procedimentos simplificados, necessidade de órgãos de controle das atividades de justiça (inclusive com a participação de leigos) etc. ${ }^{4}$.

Atualmente, várias instituições e pesquisadores pelo mundo, dentre eles Bryant Garth e Earl Johnson Jr., que atuaram com Mauro Cappelletti no Projeto de Florença, realizam uma espécie de atualização desta famosa pesquisa. Trata-se da iniciativa: "Global Access to Justice Project" ${ }^{\text {" }}$. Ela parte de tendências atuais da sociedade para analisar possíveis obstáculos contemporâneos do acesso à justiça. O objetivo é “identificar, mapear e analisar

\footnotetext{
${ }^{3}$ CAPPELLETTI, Mauro; GARTH, Bryant. Acesso à Justiça. Tradução e revisão: Ellen Gracie Northfleet. Porto Alegre: Sérgio Antonio Fabris, 1988.

${ }^{4}$ CAPPELLETTI, Mauro. Processo, ideologias e sociedade: Volume I / Tradução de Elício de Cresci Sobrinho. - Porto Alegre: Sergio Antonio Fabris Ed., 2008, pp. 389-390.

${ }^{5} \mathrm{O}$ site oficial do projeto, em sua versão em português, não traduz o seu próprio nome, pelo que preferimos manter aqui o título do projeto em inglês, mas cuja tradução seria algo como "Projeto de acesso global à justiça".
} 
essas tendências emergentes, realizando uma nova pesquisa global"6. A pesquisa ainda está em andamento "adotando uma abordagem teórica e geográfica abrangente no mapeamento e estudo do diversificado movimento mundial de acesso à justiça na África, Ásia, Oriente Médio, América Latina, América do Norte, Europa e Oceania"7.

Para além das três conhecidas ondas acima referidas, outras estão sendo consideradas: quarta onda, focada nas questões éticas das profissões jurídicas e no acesso à justiça pelos advogados; quinta onda, cujo foco é o contemporâneo processo de internacionalização da proteção dos direitos humanos; e a sexta onda, preocupada com o uso de inovações e tecnologias para o aperfeiçoamento no acesso à justiça ${ }^{8}$. Em conversa com um dos pesquisadores pertencentes ao Projeto, Diogo Esteves, ainda soubemos de uma sétima onda a ser desenvolvida, preocupada com a igualdade de gênero e étnica nos sistemas de justiça.

Normalmente, os juizados especiais são identificados na primeira e, quando muito, na terceira dimensão. Mas essas estruturas podem contribuir para o desenvolvimento de outras ondas, como a sexta, uma vez que a tecnologia é importante aliada para a consecução dos fins dos juizados. Outro exemplo são os juizados que tratam da violência doméstica e familiar contra a mulher, que ajudam no desenvolvimento da sétima onda.

Algumas conclusões parciais são possíveis.

Processos regidos pelos princípios que direcionam as atividades nos juizados especiais, elencados no art. $2^{\circ}$ da Lei 9.099/95 (oralidade, simplicidade, informalidade, economia processual e celeridade), não traduzem, necessariamente, processos que estão colaborando para um acesso mais amplo à justiça. Esses parâmetros normativos não podem ser vistos como fins em si mesmos. De que adianta, por exemplo, um processo informal, rápido, econômico, mas sem que o jurisdicionado receba a tutela jurisdicional solicitada?

Barbosa Moreira, em escrito muito conhecido ${ }^{9}$, afirmava que é um mito achar que o jurisdicionado sempre quer rapidez acima de tudo e que fórmulas mágicas (como

\footnotetext{
${ }^{6}$ Global Access to Justice Project. Historical background. < http://globalaccesstojustice.com/historicalbackground/?lang=pt-br > Acesso em 8 abr. 2021.

7 Global Access to Justice Project. "Historical Background". < http://globalaccesstojustice.com/historicalbackground/?lang=pt-br $>$ Acesso em 8 abr. 2021.

${ }^{8}$ Global Access to Justice Project. "Book Outline". < http://globalaccesstojustice.com/book-outline/?lang=ptbr > Acesso em 8 abr. 2021.

${ }^{9}$ MOREIRA, José Carlos. "O futuro da justiça: alguns mitos". Temas de direito processual: oitava série. São Paulo: Saraiva, 2004, p. 6.
} 
simplicidade ou informalidade) vão resolver os problemas da justiça no Brasil. Isso nos remete à segunda conclusão parcial anunciada.

As dimensões ou ondas foram apresentadas acima para demonstrar que os juizados especiais ocupam um papel relevante na promoção da justiça no Brasil. Alguns resumem esse papel em rapidez ou simplicidade na solução de demandas, mas há vários obstáculos que podem ser vencidos, ou pelo menos mitigados, com a ajuda dessas estruturas. Compreender os juizados especiais apenas a partir do art. $2^{\circ}$ da Lei 9.099/95, analisado a seguir, é apequená-los. Para além de obstáculos financeiros, aspectos relacionados ao uso de tecnologias, aspectos geográficos, de gênero ou etnia são fatores que, efetivamente, podem e devem ganhar atenção.

\section{BREVES REFLEXÕES SOBRE A ATIVIDADE EXECUTIVA}

$\mathrm{O}$ artigo $2^{\circ}$, da Lei 9.099/95, estabelece que, nos juizados especiais, "o processo orientar-se-á pelos critérios da oralidade, simplicidade, informalidade, economia processual e celeridade, buscando, sempre que possível, a conciliação ou a transação". Conforme Araken de Assis, é preciso "espírito aberto e sensibilidade" 10 para praticar um processo governado por esses critérios. Se isso é verdade, esse "espírito aberto" e "sensibilidade" devem ocorrer não apenas na fase de conhecimento, mas também na fase executiva.

O procedimento executivo não pode ser visto como um simples incidente de menor importância a ser resolvido. Não é correto pensar que, com a decisão, o jurisdicionado já recebeu o que veio pedir ao jurisdicionado.

Se há um dever de decidir, impedindo que o magistrado deixe de entregar a resposta solicitada pelo jurisdicionado (vedação ao non liquet), também há um dever de efetivar, compelindo o magistrado a diligenciar para evitar, na medida do possível, que o processo não termine em uma situação de inefetividade (vedação ao non factibile).

Salientar a relevância da atividade executiva não significa concluir pela efetivação a qualquer custo. A insolvência, o regime das impenhorabilidades ou a impossibilidade material da tutela específica, por exemplo, frustram a possibilidade de o credor receber a

\footnotetext{
${ }^{10}$ ASSIS, Araken de. Execução civil nos juizados especiais (livro eletrônico). 1 ed. São Paulo: Editora Revista dos Tribunais, 2014.
} 
tutela específica. Mas se o caso é, por exemplo, de um devedor que, embora ostente alto padrão de vida, não apresente bens à penhora, pois os oculta, é preciso refletir sobre a possibilidade de meios executivos que o façam adimplir.

O prévio estabelecimento dos meios executivos na lei é importante para todos os envolvidos, qualificando-se como importante pilastra da segurança jurídica dentro do processo executivo.

O magistrado que segue prima facie o que está estabelecido não é acusado de realizar execução tendenciosa. Aliás, a imparcialidade no contexto da execução é garantida quando se segue o procedimento da lei.

Durante o procedimento cognitivo, como o título executivo ainda não está formado, a imparcialidade impede que o magistrado tenha atitudes de aproximação ou hostilidade indevidas em relação a uma das partes, para que sua decisão não seja questionada. O julgador se mantém equidistante em relação às partes.

Na execução, por outro lado, o título executivo já está formado. A imparcialidade ganha novo sentido, deixando de se preocupar com uma decisão tendenciosa, pois o título executivo já existe, para focar na coibição de uma efetivação abusiva desse título. Uma forma de coibir abusos é pela observância, na maior medida possível, do procedimento préestabelecido em lei. Apenas quando ele é inadequado ou insuficiente, medidas atípicas devem ser aplicadas ${ }^{11}$.

Na perspectiva do credor, uma execução regida pela tipicidade dos atos executivos permite que ele verifique, por exemplo, quais riscos assumirá se conceder crédito a alguém.

Na perspectiva do devedor, uma execução previamente estabelecida é relevante para que ele não tenha patrimônio expropriado de qualquer maneira. Mas o detalhamento dos meios executivos em lei causa um efeito colateral pouco mencionado. É que ao saber o caminho que a execução irá tomar, o devedor pode dele desviar. Principalmente para combater situações como essas que medidas executivas atípicas podem ser úteis, mas é preciso saber se, no contexto dos juizados especiais, elas são possíveis.

\section{MEIOS EXECUTIVOS ATÍPICOS}

\footnotetext{
${ }^{11}$ MINAMI, Marcos. Da vedação ao non factibile, uma introdução às medidas executivas atípicas. 2 ed. Salvador: JusPodivm, 2020, p. 51.
} 
Meio executivo é um plano, método ou expediente adotado para se chegar a um determinado fim. No contexto da execução, o objetivo é justamente a realização da prestação constante no título executivo. Quando esses meios não são previamente estabelecidos em lei, mas criados para um caso concreto, temos os meios ou medidas executivas atípicas.

Muito já se escreveu ultimamente sobre essas medidas, com argumentos contrários e favoráveis a elas, mas é fato que o Superior Tribunal de Justiça, até agora, não os considerou indevidos, desde que respeitados alguns parâmetros e as peculiaridades do caso concreto ${ }^{12}$.

Também é importante mencionar que há, atualmente, uma Ação Direta de Inconstitucionalidade ainda não decidida sobre o tema (ADI 5.941) e que pede a inconstitucionalidade de algumas medidas atípicas, como "a apreensão de carteira nacional de habilitação e/ou suspensão do direito de dirigir; a apreensão de passaporte; a proibição de participação em concurso público; e a proibição de participação em licitação pública"13.

Este artigo vai partir da premissa de que as medidas executivas atípicas são possíveis, debatendo, apenas, se sua aplicação violaria os princípios regente dos juizados especiais ou outros preceitos da Lei 9.099/95.

\section{ORALIDADE}

O artigo $2^{\circ}$ já citado da Lei 9.099/95 apresenta os seguintes princípios regentes dos juizados especiais: oralidade, simplicidade, informalidade, economia processual, celeridade e solução consensual de conflitos. Doravante, eles serão analisados para saber se, a partir deles, medidas executivas atípicas são incompatíveis com o regime dos juizados especiais ou se devem ser evitadas.

Comentando sobre a oralidade, Felipe Borring explica que "desde a petição inicial até a prolação da sentença, os atos mais importantes do processo podem ser praticados pela

\footnotetext{
${ }^{12}$ Basta consultar: STJ. RHC 97.876/SP, Rel. Ministro Luis Felipe Salomão, Quarta Turma, julgado em 05/06/2018, DJe 09/08/2018; STJ. REsp 1.782.418/RJ, Rel. Ministra Nancy Andrighi, Terceira Turma, julgado em 23/04/2019, DJe 26/04/2019; STJ. REsp 1.788.950/MT, Rel. Ministra Nancy Andrighi, Terceira Turma, julgado em 23/04/2019, DJe 26/04/2019.

${ }^{13}$ BRASIL. STF, ADI 5941, rel. Luiz Fux. Disponível em: [www.http://portal.stf.jus.br/].

Acesso em: 9.04.2021.
} 
palavra falada"14. Mas ele também aponta atos que podem ser verbais no processo de execução, conforme previsão da própria lei especial, como o pedido executivo (art. 52, IV) e os embargos à execução (art. 53, § $\left.1^{\circ}\right)$.

Um processo regido pela oralidade não traduz a impossibilidade de meios executivos, típicos ou atípicos, até porque a oralidade é mais observada durante a fase cognitiva. Além disso, em relação aos meios executivos, é sempre recomendável que eles sejam determinados de forma escrita, para permitir um maior controle de sua realização.

\section{SIMPLICIDADE E INFORMALIDADE}

Sobre a simplicidade e informalidade várias são as leituras possíveis.

Felipe Borring aponta que, para alguns, a simplicidade pode ser entendida como um desdobramento do princípio da informalidade, da instrumentalidade ou da economia processual. Borring, contudo, prefere relacioná-la à uma adoção de linguagem simples, de fácil compreensão, para aproximar ainda mais o jurisdicionado aos serviços de justiça ${ }^{15}$.

Se a simplicidade é a adoção de uma linguagem simples, isso também não impede a adoção de medidas executivas atípicas. Uma decisão que estabeleça, em linguagem clara e simples, qual a medida a ser tomada em determinada situação é ainda mais fácil de ser aplicada do que provimentos herméticos e de difícil compreensão.

Mas e se a simplicidade não significar apenas linguagem simples, mas estiver realmente relacionada à informalidade?

Informalidade é, pelo dicionário, "qualidade do que é informal"16. O mesmo dicionário explica que informal é aquele que "rejeita formas definidas" ou "que não observa regras ou formalidades". Não é muito defensável que isso signifique autorização para o magistrado conduzir o procedimento nos juizados sem balizas. Mas se é verdade que a informalidade, em uma leitura com a instrumentalidade, significa que "os atos processuais nos Juizados Especiais poderão ser praticados sem a observância das formas não essenciais,

\footnotetext{
${ }^{14}$ ROCHA, Felippe Borring. Manual dos juizados especiais cíveis estaduais: teoria e prática. 11. ed. São Paulo: Atlas, 2021, edição eletrônica.

${ }^{15}$ ROCHA, Felippe Borring. Manual dos juizados especiais cíveis estaduais: teoria e prática. 11. ed. São Paulo: Atlas, 2021, edição eletrônica.

${ }^{16}$ Michaelis Moderno Dicionário da Língua Portuguesa. Aplicativo para celular.
} 
desde que atinjam seus objetivos, sem causar prejuízo às partes"17, então a não previsão de determinados meios executivos na lei dos juizados não significa a proibição de sua utilização.

Seria contraditório autorizar que, na fase cognitiva, atos processuais pudessem acontecer fora da ordem, ou a despeito de previsão na lei 9.099/95, mas o mesmo não pudesse ocorrer na fase executiva, quando já há, inclusive, uma decisão ou título executivo extrajudicial estabelecendo de quem é o direito a ser efetivado.

A informalidade, portanto, não invalida a possibilidade de meios atípicos, antes os validam. Resolver problemas por caminhos não previstos - porque aqueles estabelecidos são insuficientes, é fugir da formalidade ou, em outras palavras, é agir informalmente.

\section{ECONOMIA PROCESSUAL E CELERIDADE}

A economia processual "diz respeito à tomada de comportamentos necessários para que os atos processuais sejam praticados com os menores custos possíveis"18.

No procedimento executivo, normalmente, os meios sub-rogatórios são mais dispendiosos do que os meios coercitivos. Isso só não ocorre se a medida de sub-rogação for realizada na modalidade eletrônica, como no caso da penhora on-line.

Uma ordem que diga: "entregue determinado bem sob pena de multa" (meio coercitivo) custa muito menos aos cofres públicos do que determinar que oficiais de justiça busquem e apreendam determinado bem (meio sub-rogatório), sem esquecer que, em muitos casos, ainda é preciso o uso do aparato de segurança pública para o cumprimento de um mandado judicial.

Pela perspectiva da economia processual, portanto, não há empecilho no uso de meios executivos atípicos nos juizados especiais, até porque a maioria dessas medidas, ou pelo menos as mais criticadas, são coercitivas, com quase nenhum custo para o Estado. Os meios executivos atípicos podem atender à economia processual de forma mais satisfatória do que as medidas tipificadas, embora isso não signifique que a atipicidade deva preferir à tipicidade.

\footnotetext{
${ }^{17}$ ROCHA, Felippe Borring. Manual dos juizados especiais cíveis estaduais: teoria e prática. 11. ed. São Paulo: Atlas, 2021, edição eletrônica.

${ }^{18}$ CAMPOS, Eduardo Luiz Cavalcanti. O princípio da eficiência no processo civil brasileiro. Rio de Janeiro: Forense, 2018, p. 84.
} 
Quanto à celeridade, é importante apontar que o Código de Processo Civil, em suas normas fundamentais, nem fala em celeridade, mas em duração razoável do processo (artigos $4^{\circ}$ e $6^{\circ}$ ). É preciso cuidado em afirmações de que os Juizados são locais para uma justiça expressa, sem preocupação com outros aspectos. Isso foi visto em tópico acima.

O cuidado que deve haver em relação às medidas executivas atípicas, e não apenas nos juizados, mas em qualquer procedimento, é no tocante a sua limitação temporal e a sua precariedade. Este artigo não é para tratar sobre os critérios de aplicação de medidas executivas atípicas, mas essas duas peculiaridades citadas merecem detalhamento neste momento.

Os meios executivos atípicos devem atender à proporcionalidade e suas máximas: adequação, necessidade e proporcionalidade em sentido estrito ${ }^{19}$. Em relação à máxima da necessidade, "ela exige que, dentre dois meios aproximadamente adequados, seja escolhido aquele que intervenha de modo menos intenso" ${ }^{20}$. Na execução, costuma-se citar o artigo 805, do CPC, como exemplo: "quando por vários meios o exequente puder promover a execução, o juiz mandará que se faça pelo modo menos gravoso para o executado".

Canotilho aponta alguns desdobramentos da máxima da necessidade ${ }^{21}$, dos quais, para o momento, apenas um deles nos importa. A máxima da necessidade deve obedecer ao critério da exigibilidade temporal e isso, no contexto da execução civil, significa a necessidade de uma limitação temporal de medidas executivas que restringem direitos. Não é possível medida sem prazo determinado como, por exemplo: "restrição de determinado direito até que uma pessoa pague uma dívida”. Uma decisão assim viola a proporcionalidade na sua máxima da necessidade e o critério da exigibilidade temporal.

Se o magistrado determina a realização de uma conduta sob pena de uma restrição qualquer de direitos ou pagamento de multa, estabelecendo prazo para isso e, dentro do prazo estabelecido, não houver o atendimento do comando, isso significa que a medida não é apta a coagir e deve então ser alterada. As medidas executivas atípicas, nesse sentido, são

\footnotetext{
${ }^{19}$ Para um aprofundamento nesse tema específico: MINAMI, Marcos. Da vedação ao non factibile, uma introdução às medidas executivas atípicas. 2 ed. Salvador: JusPodivm, 2020, tópico 2.2.5.

${ }^{20}$ ALEXY, Robert. Teoria dos direitos fundamentais/ Tradução: Virgílio Afonso da Silva, a partir da 5. ed. alemã. São Paulo: Malheiros, 2008, p. 590.

${ }^{21}$ CANOTILHO, Joaquim José Gomes. Direito constitucional e teoria da constituição. 7. ed. Coimbra: Almedina, 2003, p. 270.
} 
temporárias (não podem ser concedidas sem prazo determinado) e precárias (se não surtirem efeitos, devem ser alteradas).

Não é demais lembrar de outra premissa para a aplicação de meios executivos, típicos ou atípicos. Se se trata de meio coercitivo, é preciso que o destinatário da coerção: a) possa realizar a prestação, mas b) não o queira fazer. Nessa perspectiva não estão na mesma situação o insolvente e aquele que esconde patrimônio. Para o primeiro, não pode haver meio coercitivo obrigando-o a adimplir.

A partir do que foi aqui colocado, é lícito concluir que a aplicação de meios executivos atípicos não viola a celeridade ou a economia processual.

\section{SOLUÇÃO CONCILIADA}

A execução depende de título executivo e inadimplemento. Talvez isso traga a falsa noção para o credor de que, se já há título executivo comprovando a prestação devida, não haveria mais espaços para uma negociação.

Ocorre que o fato de haver título executivo não significa que o devedor ou responsável secundário possuem patrimônio para honrar a prestação e isso deve ser levado em consideração a qualquer momento durante a execução nos juizados.

De qualquer modo, a possibilidade de conciliação a qualquer tempo na execução não impede que, enquanto isso não ocorra, medidas executivas sejam tomadas, típicas ou atípicas.

\section{PROCEDIMENTO EXECUTIVO DA LEI 9.099/95 E MEDIDAS EXECUTIVAS ATÍPICAS}

A Lei 9.099/95 trata, em apenas dois artigos, da fase executiva, mas isso não significa que o procedimento executivo nos juizados especiais seja regido pela atipicidade dos meios executivos.

O artigo 52 da Lei 9.099/95 estabelece que “a execução da sentença processar-se-á no próprio Juizado, aplicando-se, no que couber, o disposto no Código de Processo Civil, com as seguintes alterações [...]". Do mesmo modo, o artigo 53 menciona o CPC: "a execução de título executivo extrajudicial, no valor de até quarenta salários-mínimos, 
obedecerá ao disposto no Código de Processo Civil, com as modificações introduzidas por esta Lei”.

A partir desses artigos, algumas conclusões são possíveis.

Há uma autorização para aplicação, no que couber, do Código de Processo Civil e se alguém entender que, para a aplicação de meios executivos atípicos é necessária uma previsão legal nesse sentido, há vários artigos do CPC que podem servir para esse fim: $4^{\circ}$ (mencionando que as partes têm direito à satisfação); $6^{\circ}$ (mencionando que todos devem cooperar para uma decisão justa e efetiva); 139, IV (especificando que o juiz pode determinar todas as medidas necessárias para assegurar o cumprimento de ordem judicial, mesmo nas ações de cunho pecuniário); 297 (especificando o poder de efetivação nas tutelas provisórias) e 536 (especificando o poder de efetivação no cumprimento de sentença).

Mas é possível alguém afirmar que os artigos acima do CPC e, consequentes, as medidas executivas atípicas não são possíveis nos juizados, pois elas não atendem à locução "no que couber", presente no art. 52, da Lei 9.099/95, por possível violação ao art. $2^{\circ}$ da mesma lei. Isso não procede, conforme vimos nos tópicos acima.

O cumprimento de sentença de prestação não pecuniária (fazer, não fazer e entrega de coisa) é disciplinado em alguns incisos do artigo 52.

Em resumo, o procedimento tipificado determina a aplicação de multa coercitiva ao devedor e, caso não ocorra o adimplemento, a conversão da prestação devida em perdas e danos com consequente conversão do procedimento para execução de quantia (art. 52, V).

É possível que alguém defenda que, como aqui existe um detalhamento do caminho a percorrer, não caberiam medidas executivas atípicas. Porém, a depender do caso concreto, meios atípicos poderiam ser utilizados quando a multa não mostrasse resultado, para evitar que a execução continuasse pela tutela do equivalente. É que pode acontecer de ser mais interessante para o devedor pagar perdas e danos e a multa coercitiva do que realizar a conduta devida ou entregar o bem que não lhe pertence. Além disso, todo o regime que prestigia a tutela específica no cumprimento de sentença do CPC, como o seu art. 536, não é incompatível com o sistema dos juizados especiais ${ }^{22}$.

\footnotetext{
${ }^{22}$ Em sentido semelhante e com muito mais profundidade: ROCHA, Felippe Borring. Manual dos juizados especiais cíveis estaduais: teoria e prática. 11. ed. São Paulo: Atlas, 2021, edição eletrônica, item 2.3.
} 
Nas execuções por quantia, fundadas em título executivo judicial ou extrajudicial, em virtude da ausência de detalhamento dos meios executivos da Lei 9.099/95, normalmente, utilizam-se os preceitos do CPC como norte.

Em alguns momentos, quando a lei 9.099/95 trata das execuções por quantia, parte da premissa de que há bens penhorados (52, VII, VIII, 53, $\left.\S 1^{\circ}, \S 2^{\circ}\right)$. Todavia pode ser que eles existam, mas não se consiga a realização da penhora porque o devedor consegue ocultálos. Nessas situações, medidas atípicas são possíveis para pressionar o devedor a indicar bens penhorados ou pagar a dívida desde que existam fortes indícios de ocultação patrimonial $^{23}$.

$\mathrm{O}$ art. 53, $\S 4^{\circ}$, estabelece que quando "não encontrado o devedor ou inexistindo bens penhoráveis, o processo será imediatamente extinto, devolvendo-se os documentos ao autor". Aqui, fala-se em extinção do procedimento executivo quando não se encontra devedor ou não há bens penhoráveis. A hipótese de evidente ocultação patrimonial não autoriza, portanto, a extinção da execução e meios atípicos podem ser de grande ajuda nesse caso. Mais uma vez: há que se distinguir o tratamento deferido ao devedor que não efetua o pagamento da prestação porque não quer, daquele que se encontra em situação de insolvência, e em relação ao qual, objetivamente, não se pode exigir postura diversa.

A tese ora defendida vem ao encontro do postulado da eticidade, que, impondo-se sobre todo o ordenamento civil, resulta, em último plano, na qualificação do Direito como uma técnica a serviço de uma ética.

Uma última observação.

É possível um procedimento executivo regido pela atipicidade sem a observância prévia dos meios tipificados em lei (atipicidade antes da tipicidade) se houver acordo entre as partes nesse sentido ${ }^{24}$. Isso é dito pois a conciliação (e mesmo os embargos) na execução apenas ocorre após a penhora (art. 53, $\left.\$ 1^{\circ}\right)$. Não há mais razão para ser assim. O ideal seria

\footnotetext{
${ }^{23}$ MINAMI, Marcos. Da vedação ao non factibile, uma introdução às medidas executivas atípicas. 2 ed. Salvador: JusPodivm, 2020, p. 159; BORGES, Marcus Vinícius Motter. Medidas coercitivas atípicas nas execuções pecuniárias: parâmetros para a aplicação do art. 139, IV do CPC/2015. São Paulo: Thomson Reuters Brasil, 2019, p. 363.

${ }^{24}$ Nesse sentido: "admite-se negócio processual em que se aceite, previamente, o uso de determinadas medidas executivas atípicas, que passam, por isso, a ser medidas típicas, de origem negocial”. DIDIER JR. Fredie; CUNHA, Leonardo Carneiro da; BRAGA, Paula Sarno; OLIVEIRA, Rafael Alexandria de. "Diretrizes para a concretização das cláusulas gerais executivas dos arts. 139, IV, 297 e 536, § 1, CPC". Revista de Processo, vol. 267, mai. 2017. São Paulo: Editora Revista dos Tribunais, 2017. Versão eletrônica.
} 
possibilitar a conciliação e a defesa mesmo antes da realização da penhora. Isso, porém, é assunto para outro escrito. Mas, para quem defende a necessidade de se seguir o rito executivo previsto na lei 9.099/95, no que diz respeito à necessidade de prévia penhora para defesa e tentativa de acordo, uma provocação prévia às partes pelo magistrado pode resultar em acordo processual para que a tentativa de conciliação e mesmo a defesa ocorram previamente aos demais atos executivos, como a penhora e a expropriação.

\section{CONCLUSÕES}

As duas principais conclusões deste artigo são as seguintes:

a) os juizados especiais cumprem grande papel na ampliação do acesso à justiça que não se resume a procedimentos regidos pela "oralidade, simplicidade, informalidade, economia processual e celeridade";

b) a utilização de meios executivos atípicos nos juizados especiais não viola os princípios acima mencionados nem é incompatível ao procedimento executivo previsto na Lei 9.099/95;

c) a não ser por falta de técnica, a adoção de uma determinada medida coercitiva, por si só, não prolonga o processo "por muitos e muitos anos".

\section{REFERÊNCIAS}

ALEXY, Robert. Teoria dos direitos fundamentais/ Tradução: Virgílio Afonso da Silva, a partir da 5. ed. alemã. São Paulo: Malheiros, 2008.

ASSIS, Araken de. Execução civil nos juizados especiais (livro eletrônico). 1 ed. São Paulo: Editora Revista dos Tribunais, 2014.

BORGES, Marcus Vinícius Motter. Medidas coercitivas atípicas nas execuções pecuniárias: parâmetros para a aplicação do art. 139, IV do CPC/2015. São Paulo: Thomson Reuters Brasil, 2019.

BRASIL. STF, ADI 5941, rel. Luiz Fux. Disponível em: [www.http://portal.stf.jus.br/]. Acesso em: 9.04.2021.

BRASIL. STJ. REsp 1.782.418/RJ, Rel. Ministra Nancy Andrighi, Terceira Turma, julgado em 23/04/2019, DJe 26/04/2019. 
BRASIL. STJ. REsp 1.788.950/MT, Rel. Ministra Nancy Andrighi, Terceira Turma, julgado em 23/04/2019, DJe 26/04/2019.

BRASIL. STJ. RHC 97.876/SP, Rel. Ministro Luis Felipe Salomão, Quarta Turma, julgado em 05/06/2018, DJe 09/08/2018.

CAMPOS, Eduardo Luiz Cavalcanti. O princípio da eficiência no processo civil brasileiro. Rio de Janeiro: Forense, 2018.

CANOTILHO, Joaquim José Gomes. Direito constitucional e teoria da constituição. 7. ed. Coimbra: Almedina, 2003.

CAPPELLETTI, Mauro. Processo, ideologias e sociedade: Volume I. Tradução de Elício de Cresci Sobrinho. - Porto Alegre: Sergio Antonio Fabris Ed., 2008.

CAPPELlETTI, Mauro; GARTH, Bryant. Acesso à Justiça. Tradução e revisão: Ellen Gracie Northfleet. Porto Alegre: Sérgio Antonio Fabris, 1988.

DIDIER JR. Fredie; CUNHA, Leonardo Carneiro da; BRAGA, Paula Sarno; OLIVEIRA, Rafael Alexandria de. Curso de direito processual civil: execução. 7. ed., rev., ampl. e atual. Salvador: Jus Podivm, 2017.

executivas dos arts. 139, IV, 297 e 536, § 1º, CPC”. In. Revista de Processo, vol. 267, mai. 2017. São Paulo: Editora Revista dos Tribunais, 2017. Versão eletrônica.

Global Access to Justice Project. "Book Outline". < http://globalaccesstojustice.com/bookoutline/?lang=pt-br $>$ Acesso em 8 abr. 2021.

Global Access to Justice Project. "Historical Background". < http://globalaccesstojustice.com/historical-background/?lang=pt-br > Acesso em 8 abr. 2021.

Global Access to Justice Project. Historical background. < http://globalaccesstojustice.com/historical-background/?lang=pt-br > Acesso em 8 abr. 2021.

MAZZEI, Rodrigo Reis; ROSADO, Marcelo da Rocha. "A cláusula geral de efetivação e as medidas indutivas no CPC/15". Grandes temas do novo CPC-Medidas Executivas atípicas/ Coords.: Eduardo Talamini, Marcos Y. Minami. Salvador: Jus Podivm, 2018 . 
Rio de Janeiro. Ano 15. Volume 22. Número 3. Setembro a Dezembro de 2021

Periódico Quadrimestral da Pós-Graduação Stricto Sensu em Direito Processual da UERJ

Patrono: José Carlos Barbosa Moreira (in mem.). ISSN 1982-7636. pp. $732-743$ www.redp.uerj.br

MEIRELES, Edilton. "Medidas sub-rogatórias, coercitivas, mandamentais e indutivas no Código de Processo Civil de 2015”. Revista de Processo, vol. 247, Set/2015. São Paulo: Editora Revista dos Tribunais, 2015. Versão eletrônica.

Michaelis Moderno Dicionário da Língua Portuguesa. Aplicativo para celular.

MINAMI, Marcos. Da vedação ao non factibile, uma introdução às medidas executivas atípicas. 2 ed. Salvador: JusPodivm, 2020.

MOREIRA, José Carlos. "O futuro da justiça: alguns mitos". In. Temas de direito processual: oitava série. São Paulo: Saraiva, 2004.

ROCHA, Felippe Borring. Manual dos juizados especiais cíveis estaduais: teoria e prática. 11. ed. São Paulo: Atlas, 2021, edição eletrônica. 